\title{
The Farm Fresh Healthcare Project: Analysis of a hybrid values-based supply chain
}

\author{
Kendra Klein, ${ }^{*}$ San Francisco Bay Area Physicians for Social Responsibility \\ Ariane Michas, b Community Alliance with Family Farmers
}

\begin{abstract}
Submitted February 25, 2014 / Revised May 26 and May 27, 2014 / Accepted June 2, 2014 /
Published online November 7, 2014

Citation: Klein, K., \& Michas, A. (2014). The Farm Fresh Healthcare Project: Analysis of a hybrid values-based supply chain. Journal of Agriculture, Food Systems, and Community Development, 5(1), 57-74. http://dx.doi.org/10.5304/jafscd.2014.051.003
\end{abstract}

Copyright (C) 2014 by New Leaf Associates, Inc.

\begin{abstract}
An emerging literature on values-based supply chains offers models for meeting both the scalebased requirements and values-based goals of farm-to-institution initiatives. These models seek to incorporate conventional supply chain norms of

\footnotetext{
* a Corresponding author: Kendra Klein, Senior Program Associate, San Francisco Bay Area Physicians for Social Responsibility; 2288 Fulton Street, Suite 307; Berkeley, California 94704 USA; +1-415-350-5957; Kklein@hcwh.org

b Ariane Michas, Bay Area Regional Food Systems Manager, Community Alliance with Family Farmers; 405 14 th Street, Suite 209; Oakland, California 94612 USA; ariane@,caff.org
}

\section{Disclosures}

Both authors represent nonprofit organizations that have been leaders in the development and execution of the Farm Fresh Healthcare Project; the outcome of this research is not connected to any benefit, financial or otherwise, for either author.
\end{abstract}

efficiency, standardization, and affordability while meeting the diverse social and environmental values motivating the local food movement. Values-based supply chain models to date have been derived largely from cases of farmer cooperatives and food hubs that have purposefully designed their operations to incorporate alternative agrifood movement values. A model that deserves more attention is bybrid values-based supply chains that incorporate both conventional and alternative resources, infrastructure, and markets. Of the few studies examining hybrid models, some point to benefits such as established supply chain relationships, expertise, and infrastructure that match the needs of institutional purchasers, while others argue that conventional intermediaries reproduce marginalizing structures of mainstream supply chains. This paper explores these tensions through analysis of the Farm Fresh Healthcare Project (FFHP), a farm-to-hospital initiative in the 
San Francisco Bay Area that engages a set of hospitals' existing regional produce distributors to supply products from local small and midscale family farmers. By engaging conventional intermediaries, the project benefited from existing supply chain infrastructure shaped by norms of efficiency, standardization, and affordability. This paper analyzes the extent to which FFHP actors succeed in embedding in their supply chains a range of non-economic values, including transparency, communication of qualities of provenance and production, decision-making equity, environmental stewardship, and social equity in the form of supporting small and midscale family farmers.

\section{Keywords}

agriculture of the middle, farm-to-hospital, farmto-institution, local food movement, values-based supply chains

\section{Introduction}

Local food movement advocates are increasingly looking to institutional purchasers like hospitals, schools, and colleges as a means to scale up local food systems. Unlike the direct farm-to-customer models of farmers markets and community supported agriculture, institutional purchasers typically rely on supply chain intermediaries like distributors and processors in order to meet the logistical constraints of their foodservice operations, including the need for large and consistent volumes, preprocessed products, product standardization, and food safety requirements (Feenstra, Allen, Hardesty, Ohmart, \& Perez, 2011; Vogt \& Kaiser, 2008).

An emerging values-based supply chain (VBSC) literature offers various models for meeting both the scale-based requirements and values-based goals of farm-to-institution initiatives. These models seek to incorporate conventional supply chain norms of efficiency, standardization, and affordability while meeting the diverse values motivating the local food movement, such as mutual benefit between supply chain members, transparency, environmental stewardship, and social equity (Diamond \& Barham, 2011; Feenstra et al., 2011; Stevenson \& Pirog, 2008). While the local food movement literature has largely focused on civic values of trust, connection, and social equity (Lyson, 2004; Sage, 2003), the VBSC literature also incorporates industrial and commercial values of efficiency, standardization, and scale, which are key to addressing the challenges institutional procurement poses to the expansion of local food systems.

At the heart of redefining value in values-based supply chains is the incorporation of factors other than price in supply chain coordination, including social, health, and environmental values (Diamond \& Barham, 2011; Feenstra et al., 2011; Stevenson \& Pirog, 2008). Scholars and practitioners identify the key characteristics of a values-based supply chain as communication of qualities of provenance and production throughout the value chain; creation of strategic partnerships among supply chain members; and development of trust, transparency, and shared governance between supply chain members (King et al., 2010; Stevenson \& Pirog, 2008).

\section{Hybrid Values-based Supply Chains}

A model that deserves more attention is the bybrid values-based supply chain, which incorporates both conventional and alternative resources, infrastructure, and markets to meet the economic and noneconomic goals of farm-to-institution initiatives (Lerman, 2012). To date, VBSC models have largely been derived from cases of farmer cooperatives, food hubs, and food distributors that have purposefully designed their operations based on the goals and values of the alternative agrifood movement (Bloom \& Hinrichs, 2011; Lerman, Feenstra, \& Visher, 2012). In contrast, this paper examines a local food system network that employs distributors that did not originate in the alternative agrifood movement.

Many local food researchers and practitioners have looked to the development of new supply chain infrastructure such as food hubs, which manage the aggregation, distribution, and marketing of source-identified food from local and regional producers to help them meet wholesale, retail, and institutional demand (Barham, Tropp, Enterline, Farbman, Fisk, \& Kiraly, 2019). Food hubs offer a high degree of assurance that their supply chains embody the underlying values of the 
local food movement. However, many food hubs do not have the capital or capacity to offer the full range of services on which institutional foodservice operations rely. As one example, the majority of farm-to-institution efforts engaging cooperatives and food hubs have focused on whole products versus preprocessed products (Bagdonis, Hinrichs, \& Schafft, 2009; Berkenkamp, 2006), yet preprocessed products such as sliced zucchini or prewashed lettuce are central to the functioning of most institutional foodservice operations, since they may not have the kitchen or staff resources to prepare all ingredients from scratch (for example, see Izumi, 2008; Klein, 2012; Sachs \& Feenstra, 2008; Vogt \& Kaiser, 2008).

By engaging conventional processors and distributors, hybrid VBSCs can offer a range of relationships, expertise, and infrastructure on which institutional purchasers depend. In addition to the capacity to offer fresh-cut and other minimally processed products, conventional intermediaries can provide other "wheel and mortar" benefits, such as extensive aggregation and distribution systems, storage and refrigeration capacity, and ability to respond to shortages in the availability of targeted local products with other products from their warehouses. Engaging existing intermediaries also allows local food systems to tap into other efficiencies, such as "back haul" systems on distribution routes in which trucks are both dropping off product to customers and picking up product from producers and therefore never running empty. They can provide other benefits as well, including relationships with farmers, food safety certification and assurances, insurance coverage, and information technology (IT) and invoicing systems. In addition, hospitals report that working with an established vendor is preferable to setting up a new vendor relationship due to in-house transaction costs, both in terms of the bureaucratic systems required to add an additional vendor and the ongoing labor required to manage ordering systems for multiple vendors (multiple interviewees, personal communication, 2013).

Yet engaging conventional intermediaries may pose challenges to the underlying goals and values of farm-to-institution efforts, given that they typically function according to dynamics of price competition, economic efficiency, and economies of scale. The central question becomes, to what extent can conventional supply chain intermediaries be leveraged to incorporate alternative agrifood values?

Within the VBSC literature, the few studies examining hybrid models come to contradictory conclusions as to whether the involvement of conventional intermediaries in values-based supply chains is beneficial or detrimental to the local food movement. King et al. (2010) and Conner et al. (2011) argue that conventional supply chain players can benefit value chain development by providing unique assets, such as processing and distribution infrastructure. Izumi, Wright, and Hamm (2010) also argue for the beneficial role of regionally based food distributors, in that that they have existing relationships with local and regional farmers that can re-embed the institutional foodservice market territorially. In contrast, Bloom and Hinrichs (2011) argue that when value chains incorporate mainstream businesses, they may reproduce equity imbalances that exist in conventional food systems, and that supply chain actors need a more deliberate commitment to non-economic goals in order to establish successful mechanisms of coordination.

\section{The Farm Fresh Healthcare Project}

This paper explores these tensions through a case study of a hybrid values-based supply chain called the Farm Fresh Healthcare Project (FFHP). The FFHP is a farm-to-hospital initiative in the San Francisco Bay Area that engages a set of existing regional produce distributors to supply product from local small and midscale family farmers. While acreage or gross annual sales may help determine what counts as a small or midscale farm, hospitals and nonprofit organizations participating in the FFHP are primarily interested in farm size as an issue of market and ownership structure. The concepts of farming-occupation farms or large family farms (Hoppe, Perry, \& Banker, 2000), where farming is the chief source of income and primary occupation, are the most relevant definitions for FFHP goals aimed at supporting independent family farmers.

This study finds that the FFHP experienced both success and challenges in its aim to incor- 
porate a range of local food movement ideals into existing supply chains. The project succeeded in sourcing produce from small and midscale family farmers, increasing transparency and traceability to convey farmer identities throughout the supply chain, putting values-based criteria such as organically produced ahead of price in some purchasing decisions, and increasing communication and trust between supply chain members. The greatest challenges the project encountered were difficulties in securing full transparency throughout the supply chain due to distributor IT systems and processing logistics, barriers to the enrollment of small family farmers posed by food safety and distribution route requirements, and questions about the long-term viability and replicability of the project given its dependence on nonprofit partners external to the supply chain and its reliance on a small set of foodservice champions within participating hospitals who were willing to take on additional responsibilities and costs associated with the project.

\section{Methods}

This analysis is based on evaluation of the first year and a half of the FFHP and included interviews, participant observation, and purchasing data. The lead author conducted 11 semistructured interviews with project participants, including five interviews with two produce distributors, two interviews with two farmers, and three interviews with two hospital food and nutrition services staff members. Interviews were recorded, transcribed, and coded according to these themes: participant motivations, transparency and communication; supply chain relationships; food safety; and factors related to institutional food procurement, such as processing, volume, consistency, and standardization. Participating hospitals and distributors provided purchasing data.

Both authors represent nonprofit organizations that have been leaders in the development and execution of the Farm Fresh Healthcare Project. This allowed us the opportunity for indepth participant observation in internal conference calls, emails, meetings, and the ongoing logistics of implementing the project goals. We were guided by theories of participatory action research, which maintain that social science research can and should be conducted collaboratively with local stakeholders and with the goal of facilitating social change (Minkler \& Wallerstein, 2008 and which understand science as a contextdependent, socially constructed process in which the researcher is not a neutral observer but an engaged participant (Greenwood \& Levin, 2007). Participatory research theory provided important tools to guide a reflexive relationship to our indepth involvement in the subject of this evaluation.

\section{Background: The Farm Fresh Healthcare Project}

The first meeting of the Farm Fresh Healthcare Project in August 2011 brought together nonprofit partners, hospital foodservice leaders, and produce distributors at Kaiser Permanente's Oakland Medical Center. Major goals identified were: (1) to work through the hospitals' existing produce distributors; (2) to increase transparency in existing supply chains by tracking farmer-identified products; (3) to secure fresh-cut local produce; and (4) to source from small and midscale local family farmers,

Table 1. Farms Participating in the Farm Fresh Healthcare Project

\begin{tabular}{|c|c|c|c|c|}
\hline Farm & Acres (ha) & $\begin{array}{l}\text { Miles from San } \\
\text { Francisco }(\mathrm{km})\end{array}$ & Production & Notes \\
\hline Coke Farm & $300(121)$ & $92(148)$ & Organic & $\begin{array}{l}\text { Aggregates from } 19 \text { small-scale organic } \\
\text { farms representing an additional } 600 \\
\text { acres ( } 243 \mathrm{ha} \text { ) }\end{array}$ \\
\hline Dwelley Farms & $800(324)$ & $53(85)$ & $\begin{array}{l}\text { Mixed organic and } \\
\text { conventional }\end{array}$ & Plans to expand organic production \\
\hline Green Solar Farm & $10(4)$ & $\sim 90(\sim 145)$ & Organic & Product aggregated through Coke Farm \\
\hline Greene \& Hemly Farm & $1,100(445)$ & $82(132)$ & $\begin{array}{l}\text { Mixed organic and } \\
\text { conventional }\end{array}$ & Plans to expand organic production \\
\hline
\end{tabular}


Table 2. Farm Fresh Healthcare Project Sourcing, Summer 2012 through Spring 2013

\begin{tabular}{|c|c|c|c|c|c|}
\hline Product & Cut & Amount & Producer(s) & Distributor(s) & Hospital(s) \\
\hline Green beans & $\begin{array}{l}\text { Trimmed \& } \\
\text { cleaned, 2" } \\
\text { cut, } 1 / 4 " \text { cut }\end{array}$ & $\begin{array}{l}3,830 \mathrm{lbs} \\
(1,737 \mathrm{~kg})\end{array}$ & Dwelley Farms & Bay Cities Produce & $\begin{array}{l}\text { John Muir Health, } \\
\text { UCSF Med. Center }\end{array}$ \\
\hline $\begin{array}{l}\text { Butternut squash } \\
\text { organic production } \\
\text { methods a }\end{array}$ & $\begin{array}{c}1 " \\
\text { cubed }\end{array}$ & $\begin{array}{l}120 \mathrm{lbs} \\
\text { (54 kg) }\end{array}$ & Coke Farm & FreshPoint & SF VA \\
\hline $\begin{array}{l}\text { Strawberries } \\
\text { organic }\end{array}$ & Whole & $\begin{array}{l}8,478 \mathrm{lbs} \\
(3,845 \mathrm{~kg})\end{array}$ & Coke Farm & $\begin{array}{l}\text { Bay Cities Produce } \\
\text { Fresh Point }\end{array}$ & $\begin{array}{l}\text { John Muir Health, } \\
\text { UCSF, SF VA }\end{array}$ \\
\hline Stone fruit & Whole & $\begin{array}{l}1,440 \mathrm{lbs} \\
(653 \mathrm{~kg})\end{array}$ & Dwelley Farms & $\begin{array}{l}\text { Bay Cities Produce } \\
\text { FreshPoint }\end{array}$ & $\begin{array}{l}\text { John Muir Health, } \\
\text { UCSF, SF VA }\end{array}$ \\
\hline Cherry tomatoes & Whole & 1 flat & GreenSolar & FreshPoint & SF VA \\
\hline Apples & Whole & $\begin{array}{l}220 \mathrm{lbs} \\
(99 \mathrm{~kg})\end{array}$ & Greene \& Hemly & FreshPoint & SF VA \\
\hline Pears & Whole & $\begin{array}{l}220 \mathrm{lbs} \\
(99 \mathrm{~kg})\end{array}$ & Greene \& Hemly & FreshPoint & SF VA \\
\hline
\end{tabular}

a The butternut squash was grown on a certified organic farm; however, it was processed in a facility that is not certified organic, so the end product cannot legally be described as organic. See the discussion below for more details.

ideally those practicing environmentally beneficial production methods.

The FFHP is driven by a collaboration between two nonprofit organizations, Community Alliance with Family Farmers (CAFF) (http:// www.caff.org) and San Francisco Bay Area Physicians for Social Responsibility (SF PSR) (http:// www.CAhealthyfoodinhealthcare.org). In 2012, these organizations secured project funding through a Kaiser Permanente Community Benefit grant. Procurement began in the summer of 2012 with five hospitals: the University of California at San Francisco Medical Center (UCSF Med. Center), three campuses of John Muir Health, and the San Francisco Veterans Affairs Medical Center (SF VA). Four farms were selected to participate based on their capacity to meet the hospitals' demand for targeted produce items and their alignment with project goals (see the Project Rationale section). See Table 1 for information on participating farms.

This analysis focuses on the first year of procurement, from summer 2012 to spring 2013. Table 2 provides details on the amount of FFHP sourcing that was achieved during this time. ${ }^{1}$ (See

\footnotetext{
${ }^{1}$ By January 2014, one hospital had shifted its business to Bay Cities Produce, diminishing the importance of FreshPoint SF as a project participant. Three hospitals joined the project in 2013; however, two failed to procure significant volumes.
}

Klein, 2014a and 2014b, for recent data on FFHP procurement.)

\section{Project Rationale}

\section{Healthy food in health care}

The hospitals participating in the FFHP are leading members of the national Healthy Food in Health Care Program, which seeks to "harness the purchasing power and expertise of the health care sector to advance the development of a sustainable food system" (Health Care Without Harm [HCWH], 2014, "Strength in Numbers," para. 6). They are among nearly 550 hospitals nationwide that stand behind the Healthy Food in Health Care Pledge, which states that "for the consumers who eat it, the workers who produce it and the ecosystems that sustain us, healthy food must be

\footnotetext{
Additional farms and crops enrolled were Durst Organic Growers (400 acres or $162 \mathrm{ha}$ ), Las Hermanas (60 acres or 24 ha; aggregated through Coke Farm), and Capay Organic (2,000 acres or $809 \mathrm{ha}$ ). Total produce sourced from project inception to January 2014 was $66,659 \mathrm{lbs}(30,236 \mathrm{~kg}): 5,860 \mathrm{lbs}(2,658$ $\mathrm{kg})$ organic butternut squash, 40,072 lbs $(18,176 \mathrm{~kg})$ organic strawberries, 1,900 lbs (862 kg) organic Satsuma mandarins, 2,832 lbs (1,285 kg) asparagus, 10,615 lbs (4,815 kg) green beans, 1,484 lbs (673 kg) stone fruit, and 3,500 lbs (1,588 kg) summer squash.
} 
defined not only by nutritional quality, but equally by a food system that is economically viable, environmentally sustainable, and supportive of human dignity and justice" (HCWH, n.d.). SF PSR coordinates the Healthy Food in Health Care Program in California.

In 2006, the FFHP hospitals were among the founding members of the Bay Area Hospital Leadership Team coordinated by SF PSR, which seeks to put this vision of healthy food into practice by sharing information and pooling institutional purchasing power. Prior to the FFHP, they had already achieved success on alternative food procurement projects (e.g., see HCWH, 2012), and two of the hospitals had won national recognition for their leadership on local and sustainable food efforts (Harvie, 2008; Sirois, Pryor, Klein, \& Thottathil, 2013).

The FFHP benefited from a great deal of prior learning and changes to systems of operation with the goal of incorporating local, seasonal foods into their menus. For a hospital, changes in food procurement hinge on menu planning, which typically involves a team of dietitians developing targeted diets for all of the hospital's patients. Changes can take weeks or months of planning and paperwork. One hospital representative noted their increased nimbleness in menu planning and related ordering processes as key to FFHP success, "In the past we've taken a whole quarter to incorporate seasonal produce. . . [but] only two weeks ago on a Tuesday I said, 'asparagus is coming on,' and by Friday, our executive chef was announcing menu changes. I was blown away. You keep at it, and finally there comes a day when, hey, we're pretty good at this now" (Interview \#71, 2013). Another hospital representative noted that they had synchronized cafeteria menus with order guides, so that, when the executive chef changes the menus from, for example, winter squash to asparagus, it automatically triggers a change for the staff member coordinating online ordering (Interview \#74, 2013).

\section{Prioritizing local family farmers}

Prior to and during the FFHP, participating hospitals were sourcing and tracking local produce through their produce distributors, Bay Cities
Produce and FreshPoint San Francisco. ${ }^{2}$ Both distributors developed local food programs in response to customer demand, but they rely solely on geographic distance in their definition. Bay Cities Produce uses a series of concentric zones it calls Local 1, 2, and 3: Local 1 (L1) refers to food produced within 100 miles $(161 \mathrm{~km})$ of the company's warehouse in San Leandro, California (CA); Local 2 (L2) extends the circle to 250 miles (402 km); and Local 3 (L3) refers to food produced within the state of California (Bay Cities Produce, n.d.). FreshPoint San Francisco defines two spatial zones: food produced within 150 miles $(241 \mathrm{~km})$ of their warehouse, and food produced within California.

The FFHP sought to incorporate a broader set of criteria than geographic distance in its definition of local food to "define local and sustainable purchasing in a much deeper way," according to one participating hospital representative (Interview \#71, 2013). Definitions of local food that rely on geographic distance do not take into account ownership structure of farms or agricultural production methods. While buyers may envision supporting small-scale family farmers, local economies, and environmentally beneficial agricultural techniques, ascertaining the distance between food production and the end consumer is no guarantee that it embodies those values (Hinrichs, 2003; Selfa \& Qazi, 2005). This is particularly true in California where a highly industrialized form of agriculture has been dominant for over a century (Guthman, 2004; Walker, 2004). California's US $\$ 43.5$ billion agricultural economy produces nearly half of U.S.grown fruits, vegetables, and nuts (California Department of Food and Agriculture, n.d.), making fresh produce grown on an industrial scale readily accessible. While local is often associated with an agrarian ideal, California boasts such local farms as Grimmway, the world's largest producer of carrots,

\footnotetext{
2 Three FFHP hospitals use Bay Cities Produce and one uses FreshPoint San Francisco. Both distributors source from producers and wholesalers locally, nationally, and globally based on factors of cost and supply. Bay Cities Produce is an independent, family-run produce company founded in the Bay Area in 1947. FreshPoint SF is a subsidiary of the national food distributor Sysco. It was formerly the independent regional distribution company Lee Ray-Tarantino.
} 
processing over 10 million pounds [4.5 million $\mathrm{kg}$ ] weekly (Blatner, 2012).

During the initial planning phase of the FFHP, a collaboration between the hospital leadership team and nonprofit partners SF PSR and CAFF resulted in the following definitions of local food:

- Tier 1 - Locally produced on small to midscale family farms: Farms, ranches, and production and/or processing facilities located within a 250-mile $(402-\mathrm{km})$ radius of the hospital facility.

- Tier 2 - Sustainably grown: Food that carries one or more independent third-party certification focused on sustainable production practices, is USDA Certified Organic, or is in transition toward achieving organic certification.

- Ultimate goal: Locally grown on small family farms using sustainable farming practices; free of toxic pesticides and genetically modified organisms (GMOs).

The threefold intent of the criteria was to support a segment of the agricultural sector that has been identified as threatened and in need of new market opportunities (Kirschenmann, Stevenson, Buttel, Lyson, \& Duffy, 2008), to support agricultural practices that are more environmentally sustainable, and to prioritize organic produce in order to decrease farm worker and hospital patrons' exposure to potentially harmful pesticides.

\section{Choosing a bybrid supply chain structure}

The hybrid supply chain structure of the FFHP is the result of a learning process within a network of farm-to-institution actors in the San Francisco Bay Area. In particular, it can be understood as a response to the experience of a food hub called the Growers' Collaborative (GC) and a result of the maturation of existing regional distributors' interest in local food sales.

In response to the experience of the GC, the FFHP set out not to "reinvent the wheel," but to retrofit the existing supply chain to become shorter, more flexible, and more transparent. With some of the participating hospitals sourcing up to 90 percent of their fresh fruits and vegetables in processed form (e.g., sliced green beans and cubed squash), the FFHP also sought to engage intermediaries that could help "crack the nut" of supplying fresh-cut product in addition to whole product.

The history of the GC points to some of the logistical and capital challenges associated with developing new supply chain infrastructure (Abellera, Del Signore, Derden-Little, Michas, Runsten \& Sabato, 2014)). CAFF founded GC in 2004 in an effort to scale up the local food system. ${ }^{3}$ The decision to create new food system infrastructure was influenced by a desire for transparency, traceability, and the ability to incorporate participating farmers' stories into product marketing, factors which were not perceived as possible through existing distributors at the time.

Even at the height of its operation, GC struggled with structural inefficiencies like a limited number of vehicles, which restricted aggregation capacity, and sub-par storage facilities with inadequate refrigeration space, poor drainage, and insufficient access for trucks. In addition, GC could not draw on the economies of scale and professional savvy of larger farms and could not offer the full complement of a year-round product list that its customers were accustomed to. As one participating farmer remarked, " $[\mathrm{GC}]$ might take two cases of tomatoes, but you need to have a bunch of other products to spread out the costs. Does it warrant the gas, the cost of the employee to deliver? [GC] was a fantastic concept, but unless you're able to provide a wide range of products like a wholesale distributor, you lose that efficiency" (Interview \#78, 2013). Ultimately, the challenges of scale and structure associated with setting up a parallel distribution business from scratch were insurmountable for the Growers Collaborative.

Despite its shortcomings, GC built enthusiasm, demand, and knowledge about local food within institutional foodservice in the regions it

\footnotetext{
${ }^{3}$ GC was founded through a USDA Value Added Producer grant. By 2006 it served the Ventura Unified School District, Kaiser Permanente medical centers, corporate and university cafeterias administered by Bon Appetit Management Company, the campuses of the University of California, Davis, and University of California, Berkeley, two additional school districts, and Revolution Foods.
} 
served. In addition, GC demonstrated to regional produce distributors that there was a high level of demand for local produce in their customer base. A number of these distributors began to develop local sourcing programs, in many cases approaching CAFF for technical assistance.

\section{Discussion}

The Farm Fresh Healthcare Project can be understood as an example of a values-based supply chain aiming to meet both the scale-based requirements and values-based goals of participating hospitals. By engaging conventional intermediaries, the project was able to benefit from existing supply chain infrastructure shaped by norms of efficiency, standardization, and affordability. The central question this analysis seeks to clarify is to what extent FFHP actors succeeded in embedding a range of non-economic values in their supply chains, including transparency, communication of qualities of provenance and production throughout the supply chain, decision-making equity between supply chain members, environmental stewardship, and social equity in the form of supporting small and midscale family farmers.

Among the benefits of engaging conventional distributors were taking advantage of existing distribution routes; the regularity of the distribution schedule (both distributors deliver up to five times weekly to the hospitals); ability of both distributors to respond immediately to shortages in targeted produce with other products; infrastructure that included refrigerated trucks, warehouses with necessary refrigeration, and Bay Cities' in-house processing capacity; avoiding the need for hospitals to create new vendor accounts; and food safety assurances. Bay Cities' customers commented that their high level of trust in the company's foodsafety practices influenced their desire to have local produce come through that channel. Food-safety certification is a top priority for hospitals due to the immune-compromised patient population they serve and the strict foodservice inspections administered by the state, in accordance with standards set by the Centers for Medicare and Medicaid Services, to which they must adhere. Bay Cities Produce has developed state-of-the-art food-safety systems in its processing facilities and warehouse, including microbe testing of each batch of cut product, a practice that is currently far beyond the industry standard.

As the following discussion demonstrates, the FFHP experienced both success and challenges as it sought to incorporate a broad range of social, health, and environmental values into existing supply chains.

\section{Supply Chain Transparency}

One of the underlying tenets of the FFHP and the alternative agrifood movements from which it emerged is that the qualities of a food's production, processing, and distribution have implications for the health of people, communities, and the environment. While conventional supply streams are coordinated predominantly by price and economic efficiency, the FFHP and similar farm-to-institution initiatives prioritize food with a history that embodies a broader range of values and goals. Thus mechanisms of transparency are central to values-based supply chain models in order to communicate such crucial characteristics as local provenance, conservation techniques, or ethical standards to final consumers (Cohen \& Derryck, 2011; King et al., 2010; Lerman, 2012). This information is typically not readily available to buyers in conventional supply chains, which focus on price and measurable quality characteristics such as weight or pack size as the predominant factors of relevance (Feenstra et al., 2011).

Although FFHP hospitals had previously been sourcing local produce through their regional distributors, prior to the project they knew little about the source of the products beyond geographic distance and had no mechanism for prioritizing certain growers. As one hospital representative stated, "We can now order directly through our produce company for a specific farm, we never had that before, we could only know after the fact [on invoices] if it was locally sourced, and we didn't know anything about the farm or the farm practices" (Interview \#74, 2013).

Embedding the product with information all the way through the supply chain is central to the ability of hospitals to "pull" product through the system by prioritizing a specific farm when they're ordering, to track their purchasing progress, and to 
know when the product is in-house so they can "tell the story" of the product to patients, staff, and visitors.

\section{Existing Mechanisms of Transparency}

There were some important systems of transparency already in place in relation to each distributor's definition of "local" based on geographic distance from their facilities. In response to customer demand for local products, Bay Cities offers a fresh-cut blend of root vegetables from farmers in the Brentwood region labeled as a Brentwood Mix on ordering sheets and packaging. Bay Cities also includes demarcation of its three local zones, L1, L2, and L3, on invoices. Upon customer request, it will produce a local purchasing report based on these zones.

FreshPoint SF publishes a weekly "hot sheet" of locally produced items. More recently, FreshPoint SF has become a business member of CAFF's Buy Fresh Buy Local program. Marking products with the Buy Fresh Buy Local logo demarcates them as products grown by $\mathrm{CAFF}$ member farmers. The hot sheet lists item codes, cost, product name, farm name, farm location, and distance to the FreshPoint SF warehouse. Customers can not request product from particular farmers, but if customers order a product on the hot sheet, they can trust that it was produced by the listed farmer. FreshPoint SF's invoices include demarcation of $L$ for items produced within 150 miles for their facility, $C A$ for items produced within California, and $O$ for organic products. Upon request FreshPoint SF staff will run sales reports using specific product codes and will run general local purchasing reports for customers.

\section{The Need for New Technology Systems}

Achieving the level of transparency aimed for by FFHP hospitals and nonprofit partners in terms of identifying farm names throughout the supply chain - at point of sale, on invoices, and on packaging for fresh-cut produce - would require significant changes in tracking systems, with the biggest stumbling block being distributor IT systems. Although distributors already trace every batch of whole and processed product to the farm out of concern for food safety, they do not have systems in place to incorporate that information into hospitals' ordering sheets or onto packaging for processed products.

Currently, Bay Cities Produce and FreshPoint SF assign a product code according to product type; for example, all $3 / 4$ " $(1.9 \mathrm{~cm})$ cut green beans have the same code. Creating an individualized product code for farm-identified products, like Dwelley Farms green beans, was bound up with a host of system changes. One distributor representative remarked that, "The in-house frustrations, the difficulties with order entry, they are just monumental" (Interview \#72, 2013). The challenges were due in large part to the fact that the current information technology (IT) systems were built around an assumption that farm name does not matter. Without access to updated IT systems for the duration of the FFHP, all the necessary changes had to be done manually. For example, Bay Cities created overrides in its computer system so that when the FFHP hospitals ordered green beans, it would automatically show that they wanted Dwelley Farms green beans.

The type of software that can handle farmer identification exists. It has been developed by intermediaries that see value in communicating qualities of provenance and production. One example is Veritable Vegetable, an organic produce distributor in San Francisco. This company has developed a proprietary software system that lists farm names on order sheets, allowing customers to weigh factors like farm origin in addition to price. Other examples are Local Orbit, a company that provides software platforms and business management to "re-link the food chain" (Local Orbit, n.d.) and Market Maker, an interactive database that connects food producers to new markets supported by partnerships between land-grant institutions and state departments of agriculture in 10 states.

Both distributors state that they plan to invest in software that could track farm names or other relevant characteristics throughout the system. In the meantime, FFHP participants have brainstormed ways to ensure transparency while incurring fewer transaction costs. One distributor suggested that rather than create individualized product codes, he might share his production log with hospitals and nonprofit partners weekly or 
allow them to spontaneously request to see purchase slips for a given day. Yet this after-the-fact reporting doesn't allow the hospitals to choose one product over another based on provenance, farm scale, and production practices. Having that choice is central to institutions' ability to influence change within the food system.

SF PSR and CAFF initiated conversations around creating a Buy Fresh Buy Local product line that would operate like Bay Cities' Brentwood Mix. This would be a shift from tracking a specific farm's product through the processing room to using an identified line of product sourced from farmers who meet the criteria of the project, in this case CAFF member farmers participating in the FFHP. ${ }^{4}$ This would allow greater ease in relation to the distributors' ordering and processing systems, potentially allowing a more rapid expansion in the number of farmers and products incorporated in the FFHP.

\section{Transparency and Fresh-cut Produce}

During the pilot year of the project, the FFHP succeeded in supplying hospitals with fresh-cut green beans labeled by farm name at point of sale and on the product package. This represents a significant improvement in transparency and was achieved with a great deal of effort. Typically, once product enters the processing facility it becomes anonymized. In order to fulfill a set of orders for cut green beans, a processor may combine product from a number of farmers. Tracking a specific farms' product all the way through processing resulted in different challenges for each distributor, based on the structure of their operations. Bay Cities was more nimble as a result of having an inhouse processing room, but having to organize processing and labeling around set batches of Dwelley Farms green beans resulted in high transaction costs:

You've got to stop all the presses and make different labels, get them on the bag, see who

\footnotetext{
${ }^{4}$ In November 2013, Bay Cities Produce became a CAFF business member and began working on a line of Buy Fresh Buy Local fresh-cut blends incorporating FFHP produce, a root vegetable mix, braising mix, and stir-fry mix.
}

gets what - is UCSF going to get the DF label today? Is John Muir? If I have to create labels for all of these farms, you can imagine. If it's just beans it's not that bad, but for me, beans represents an easy dozen items that I need to process - my different blends, cleaned and trimmed, half-inch $[1.3 \mathrm{~cm}]$, twoinch $[5 \mathrm{~cm}]$, three-inch $[7.6 \mathrm{~cm}]$ - all of those labels have to be changed if we run out of that lot and have to go to another lot. (Interview \#72, 2013)

FreshPoint SF is purely a distribution company, not a processor-distributor. To supply customers with cut produce, it sources from other facilities across the country. The majority of its green beans, for example, come from a processing facility in Ohio. It wasn't able to make the logistics of dealing with a local processor work successfully in order to supply its FFHP hospital with freshcut Dwelley Farms green beans. However, as discussed below, it renewed its efforts in the winter with butternut squash and was able to make the mechanics of the arrangement work, albeit in small volume.

\section{Telling the Story to Hospital Staff and Patrons} Participating hospitals kept the story of the FFHP produce intact all the way through to the end consumer. The hospitals were interested in conveying their involvement in the FFHP to patients, staff, and cafeteria visitors as a way to advertise and promote the extra effort they are making to undertake values-based purchasing and to educate hospital patrons about local and seasonal foods. One hospital representative remarked, "We don't want to just say we purchase local, we want to tell stories about great farmers. By telling those stories within a great institution, we can lead; because we are who we are, people look up to us and study what we're doing" (Interview \#71, 2013). In order to ensure that the story of the FFHP did not stop at the plate, CAFF produced posters, farmer profiles, and tray cards for the participating hospitals. The materials used the Buy Fresh Buy Local branding and included information about FFHP farmers and the motivations behind the project. 
Supporting Small and Midscale Family Farmers

The FFHP specifically aimed to support small and midscale family farmers with its stated ultimate goal being support for smaller-scale farmers practicing conservation-based production methods. The process of identifying farmers for the FFHP provides insight into the tensions between conventional and alternative values and goals that were negotiated within the project.

Aligned with recent literature on the agriculture of the middle, which predicts that midscale farms have a comparative advantage over small farms in terms of supplying product to institutional buyers (Kirschenmann, Stevenson, Buttel, Lyson, \& Duffy, 2008), the FFHP found that midscale farmers were the most likely to meet the volume, pack and grade standards, and food-safety criteria required by distributors and hospitals while also embodying the social and environmental values driving the project. This supports the theory put forward by the Agriculture of the Middle Project that institutional buyers can serve as an important market for midscale farms (Lyson, Stevenson, \& Welsh, 2008). Midscale farmers are typically too large to survive on direct marketing like farmers' markets, but struggle to succeed in highly consolidated commodity markets, making them the most threatened segment of the farm sector (Kirschenmann et al., 2008).

CAFF initially identified two midscale family farms for the project that were food-safety certified and carried a range and volume of products that made it worthwhile for the distributors to send a truck to the farms for pick-up. As one distributor representative remarked, "It costs me US\$80 to US $\$ 100$ to stop my truck, so there's got to be some scalability" (Interview \#75, 2013). Likewise, another distributor representative noted the importance of scale in terms of fuel efficiency: "The freight thing we were able to work out to where we were able to pick up enough items in that general area so that I didn't waste a truck all the way out to grab a pallet. That's huge for my Green Certificate; if I run a truck out for 60 boxes and it holds 1,200, I'm really high on my carbon footprint" (Interview \#72, 2013).

The need for distribution efficiencies acted as a barrier to smaller-scale farmers. Yet the FFHP succeeded in sourcing cherry tomatoes from one very small-scale farm, 10-acre [4-ha] Green Solar Farm. This was achieved as a result of Coke Farm acting as an aggregator for 19 smaller farms, including Green Solar, allowing the distributors to source from those operations without making additional trucking runs.

Food safety is a central criteria for hospitals, and Bay Cities Produce and FreshPoint SF both require the majority of their farms and products to be food-safety certified by a third party. This, too, can act as a barrier to smaller farms. While the cost of becoming third-party food-safety certified does not constitute a huge business expense (costing approximately US $\$ 3,000$ ), the ensuing documentation processes are time- and labor-intensive, representing many tens of thousands of dollars in farm employee time. Most small farms struggle to afford this additional cost. Midscale farms must find a way to absorb the cost in order to fully market their harvests, since food-safety certification is increasingly essential to entry for wholesale markets. One participating midscale farmer explained that over the past four years, his farm had taken on multiple food-safety certifications to reach different markets: "There's the small farm GAP program, and then there's Primus, and there's SQF2000 Global, so you can send your product anywhere in the world, and that's where we are now" (Interview \#78, 2013). Multiple FFHP supply chain members have a commitment to help small and midscale farmers get food-safety certified. Both Bay Cities Produce and FreshPoint SF offer scholarship programs to interested farms, and CAFF has a food-safety expert on staff who works with small farms to implement food-safety plans.

Product specifications also acted as a barrier. The FFHP attempted to supply cut butternut squash from Coke Farm through Bay Cities Produce, but Bay Cities found the squash was too small for efficient and cost-effective processing and declined to use it. One hospital representative remarked that Bay Cities' specifications for product size impacts their method of identifying farms to source from: "Now the approach is not so much to pick a farm we want to work with as much as ask Bay Cities who they're working with who fits our objectives" (Interview \#71, 2013). Although the 
FFHP may be able to identify other farmers who meet both the hospitals' and distributors' needs, this points to the ways in which the logistical needs of institutional foodservice operations may limit the type of farmer who is able to benefit from farm-to-institution procurement initiatives.

During the evaluation process it became evident that the incorporation of farm scale in FFHP definitions of local food produced interesting tensions in relation to farmer-distributor relationships. One distributor representative stated, "My alliance is to the people who helped get us started, even though they could be huge now. My first goal is to support those who supported us - loyalty" (Interview \#72, 2013). While the FFHP criteria related to farm scale align with alternative agrifood goals, the distributor's hesitation to displace business to new farmers demonstrates one way the FFHP definition could conflict with another value prevalent in the VBSC literature: durable relationships marked by mutual benefit.

\section{Decision-making Equity}

While the VBSC literature envisions decisionmaking equity between all supply chain members, the hospitals in the FFHP retained the highest degree of decision-making power, while farmers were engaged more as suppliers than as equal members and distributors were tasked with meeting hospitals' new demands.

The strength of the hospitals was greatly increased by their collaboration through the Hospital Leadership Team, in which they combined their purchasing power for a set of mutually agreed upon products. Along with pooling purchasing power, ongoing collaboration through the Hospital Leadership Team coordinated by SF PSR includes conference calls and roundtable discussions between the hospitals on challenges, implementation strategies, and alternative food purchasing goals. In the case of the FFHP, this collaboration also provided gentle peer pressure among the hospitals that helped to encourage all facilities to commit to price increases, particularly in relation to organic strawberries, as discussed below.

Together, the FFHP hospitals represented the majority of health care customers of one of the distributors and approximately 15 percent of his total green bean sales. Noting the importance of this type of combined demand, one hospital representative stated, "If everyone is independent, no one is going to be able to drive this huge system forward, but if we have three or four hospitals, that's a game changer. All of a sudden, our distributor is listening to everything we have to say" (Interview \#71, 2013). As a result, hospitals held the greatest decision-making power in the FFHP, by pulling products through the system.

\section{Communication and Relationship-building Between Supply Chain Members}

The FFHP resulted in increased communication and contact along the supply chain, leading to greater understanding of the needs of other supply chain members. Communication took the form of conference calls and in-person meetings facilitated by SF PSR and CAFF, and farm visits coordinated by one hospital representative and one distributor. CAFF also played a crucial role in facilitating communication along the supply chain through an extensive amount of one-on-one calls with distributors and hospitals, conveying information back and forth.

A representative of Coke Farm noted the importance of increased communication with hospitals in relation to crop planning. Based on hospital commitment to purchasing her organic strawberries, she was able to manage her production schedule for the coming year to meet that demand. She also learned about the constraints facing hospital foodservice staff, remarking that, "It opened up my eyes to how much time it takes them to plan and to get something on the menu and how many factors they have to think about, like compatibility with all the different nutritional requirements for patients" (Interview \#73, 2013).

Relationships between supply chain members were further facilitated by a series of farm visits. Initially, one hospital representative was inspired by the project to take personal trips to participating farms, sharing photos and stories with other hospital members. In the second year of the project, Bay Cities organized a trip to Dwelley Farms for all of its hospital customers, including several that were not already FFHP members, three school districts, and two high-tech company cafeterias. 
Bay Cities' willingness to take on this extra project signals recognition of its customers' increasing interest in building connections with specific farmers. On the farm tour, hospital representatives learned about issues of farmland preservation, farmworker concerns, food-safety practices, and the impacts of weather on production. Afterwards, they reported having a stronger sense of why their long-term commitment to individual farmers matters. Through a VBSC lens, this is a significant success as personal relationships come to take precedence over, or at least stand alongside, price in purchasing decisions.

The distributors reported the value of the nonprofit organizations' involvement in the FFHP and the local food movement in general. "What's really helpful to me [about the project] is the connecting, the networking, the flow of information; CAFF has tipped me off to farmers, that's valuable information," stated one distributor representative (Interview \#76, 2013). Another commented on the benefits of what he perceives as local food advocates' increasing understanding of issues of scale and standardization:

CAFF has realized that food safety is a real deal. They understand that they can't put me in a position of being vulnerable, because I'm only as strong as my weakest link. They understand that they can't send me a farm that, number one isn't large enough to sustain volume and that doesn't have some sort of good agricultural practice - this is a huge transformation. (Interview \#72, 2013)

These examples point to the value of communication for building trust between supply chain members, as well as the relevance of taking the time to understand the needs and constraints facing other members. For farm-to-institution initiatives in general, and for hybrid values-based supply chains specifically, this type of mutual learning is central to effectively combining local food ideals with conventional supply chains values and practices.

Prioritizing Organic

During the planning phase of the FFHP, participating hospitals indicated a high level of interest in organic produce given the growing body of data linking pesticides used in conventional agricultural production to a host of adverse health and environmental impacts (Alavanja, Hoppin, \& Kamel, 2004; Sutton, Wallinga, Perron, Gottlieb, Sayre, \& Woodruff, 2011). One hospital representative explained the connection he sees between organic produce and the role of health care organizations by referring to the "Dirty Dozen" list of produce most heavily contaminated with pesticide residues generated by the Environmental Working Group (http://www.ewg.org). "I would like to get our foodservice department to line up behind a commitment to not buy the twelve most heavily sprayed produce items. Strawberries are on that list. Right now, organic strawberries are so expensive, but we are making that kind of statement as a medical center" (Interview \#71, 2013).

The FFHP hospitals paid up to twice as much for Coke Farm's organic strawberries as they would have for conventionally grown berries. The hospitals' willingness to pay additional costs for products that met their health and environmental values aligns with other findings on farm-to-institution initiatives, which show that these programs are growing in number and popularity despite higher costs (Feenstra et al., 2011). The 8,748 pounds $[3,968 \mathrm{~kg}]$ sourced from Coke Farm represented the four pilot hospitals' total demand for strawberries over the course of the summer growing season.

The hospitals' commitment to Coke Farm resulted in a greater proportion of local sales for the farm and an increase in its strawberry acreage. Rather than sell to established customers in locations like Denver and Chicago, the farmer shifted sales to the local hospitals. In addition, Coke Farm increased its acreage of strawberries by approximately thirty percent for the next summer growing season in order to meet the demand of FFHP hospitals, stating that, "in California the markets can be saturated with so many farms, so diversifying the customer base is really great. Both distributors [involved in the FFHP] are now buying a little more of my product across the board, and they were really supportive of the strawberry growing season" (Interview \#73, 2013). 
The FFHP hospitals passed price premiums on to customers or absorbed them in their budgets. One facility, for example, found ways to save on its foodservice linen budget in order to cover the increased cost of the FFHP strawberries. This points to one challenge to the expansion of the FFHP, since budgets can only be reworked to find hidden savings so many times. In addition, covering the additional cost of the FFHP strawberries was possible only because they represented a relatively small proportion of hospitals' overall budgets, raising questions about the hospitals' ability to expand this type of purchasing.

\section{Project Stability and Replicability}

In addition to these budgetary concerns, two aspects of the FFHP raise questions about its longterm viability and replicability. First, if in-hospital champions leave before new procedures are institutionalized, conventional market forces are likely to reassert their dominance. Second, the external expertise and investment of nonprofit partners was necessary to keep the project moving. As Cohen and Derryck (2011) found, the involvement of nonprofit organizations in values-based supply chains can be "key to creating a food production and distribution system that engages a wide range of stakeholders, fosters shared governance and transparency, empowers consumers, and benefits regional farmers" (p. 85). In locations where nonprofit organizations are not present or not able to raise funds for farm-to-institution projects, the FFHP model may not be applicable.

The process of securing cut butternut squash illustrates the central role that nonprofit partners played in the success of the FFHP. In this case, a number of logistical challenges arose that created inefficiencies that the distributors would not willingly take on without a good deal of external pressure. Although hospital foodservice members of the FFHP had the desire to make the purchasing arrangements happen, they did not have the time to continue following up and pressuring distributors. Ultimately, the FFHP succeeded in providing cubed, organically grown butternut squash from Coke Farm to the SF VA through FreshPoint SF. Although the total volume sourced was quite small (120 pounds or $54 \mathrm{~kg}$ in total), the success lay in creating supply mechanisms that could be replicated with other products, as was the case with cut summer squash during the summer of 2013.

Since FreshPoint SF does not have in-house processing, it worked with Legacy, a local processor, to cut butternut squash for the SF VA. Although the squash was organically grown, Legacy is not an organic-certified processor, so the final product could not legally be labeled organic. To maintain the organic integrity of the product, Legacy agreed to only process Coke Farm's squash first thing in the morning before other product had gone through the clean equipment. Another challenge involved liability and ownership of the product. Due to issues of liability, FreshPoint SF had to transfer ownership of the product to Legacy and then buy it back before selling it to the hospital. It took many weeks to wrangle this arrangement, by which time winter squash season was winding down. Coke Farm's representative perceived that her product would likely have not reached the SF VA without CAFF's involvement, commenting that "I'm afraid that [they] really have been the grease to keep it going, to keep people on task and to keep them motivated and see the bigger picture. I am a little bit worried about that" (Interview \#73, 2013).

The FFHP represents a departure from business as usual and therefore has required the development of new relationships, systems, and mechanisms of coordination. It remains to be seen whether FFHP purchasing patterns will continue once CAFF and SF PSR are no longer funded for this particular project. The organizations' goal is to help build supply chain relationships and mechanisms that will guarantee ongoing success even without their external support. One hospital representative sees this as a possibility, stating, "I see this as a strategy where eventually we get so good at lining ourselves up that we come across a great farmer and our distributor knows what to do. We'll open up a communication channel for the next season and we'll move together in sync" (Interview \#71, 2013).

\section{Conclusion}

As the local food movement seeks to expand in order to reach institutional buyers like hospitals 
and schools, researchers and practitioners will increasingly need to understand how best to engage supply chain intermediaries that are able to meet the needs of institutional foodservice operations while (re)building local and regional food system infrastructure. While continuing to pursue the development of new supply chain infrastructure such as food hubs and cooperatives, increasing attention should be turned to creating and analyzing hybrid values-based supply chains that use both conventional and alternative resources, infrastructure, and markets to achieve a broad set of value chain goals.

As an example of a hybrid values-based supply chain, the Farm Fresh Healthcare Project experienced both successes and challenges in its aim to incorporate a range of local food movement ideals into existing supply chains. The project succeeded in sourcing produce from midscale family farmers as well as one small-scale farmer; increasing transparency to convey farmer identities throughout the supply chain; putting values-based criteria such as organically produced ahead of price in some purchasing decisions; and increasing communication and trust between supply chain members.

The greatest challenges to transparency that the project encountered were the lack of distributor IT systems capable of communicating farm names on order sheets and invoices, as well as the logistical hurdles of segregating farm-specific products to send through the processing room, whether it was in-house (Bay Cities) or outsourced to a local processor (FreshPoint SF.) Both distributors involved in the project express plans to purchase and implement updated IT systems in the future, demonstrating that initiatives like the FFHP have an opportunity to impel conventional intermediaries to learn from and adopt the technologies and mechanisms that have been developed within alternative agrifood supply chains.

The greatest challenges to meeting the hospitals' desire to source from small-scale farmers were distributors' need for distribution efficiencies, processor production specifications, and hospital and distributor food safety requirements.

Like the hybrid value chains examined by Conner et al. (2011) and Cohen and Derryck
(2011), advocacy organizations played a key role in ensuring the incorporation of alternative agrifood goals in the FFHP. This poses a potential challenge to the replicability and long-term durability of the FFHP, since nonprofit participation depends on external funding.

Other challenges to long-term durability are the extent to which the project relied on a small set of foodservice champions within participating hospitals. In order to achieve project goals, the hospital members of the FFHP were willing to deal with certain inefficiencies and to work through processes of trial and error. Aligned with Feenstra et al.'s (2011) analysis of the factors that affect the sustainability of farm-to-institution initiatives, FFHP hospitals were willing to try new procedures even if they were messier and were willing to adjust for price increases. If these purchasing priorities and procedures are not institutionalized, conventional market forces are likely to reassert their dominance once FFHP advocates are no longer managing foodservice decisions in participating hospitals. Finally, hospital budget constraints make FFHP purchasing patterns tenuous without encouragement and continuous commitment from within the hospitals, from peer hospitals, and from nonprofit partners.

Although it is beyond the scope of this paper, it is important to note that there may be broader food-system benefits to engaging existing regional intermediaries in the local food movement. Due to trends of consolidation in the food system, the intermediaries that could give local and regional farmers wider access to retail, institutional, and commercial foodservice markets are being squeezed out, leaving an increasingly bifurcated system that favors small-scale direct markets and large-scale commodity markets (Gereffi, Lee, \& Christian, 2009; Kaufman, Handy, McLaughlin, Park, \& Green, 2000; Martinez, 2007; Perrett, 2007). Although farmers often take center stage as the beneficiaries of the local food movement, supporting independent regional intermediaries may be just as important to achieving goals related to community building and supporting local economies. 


\section{References}

Abellera, D., Del Signore, D., Derden-Little, E., Michas, A., Runsten, D., \& Sabato, M. (Eds.). (2014). Making the invisible visible: Looking back at fifteen years of local food systems distribution solutions. Retrieved from the Community Alliance with Family Farmers website: http://caff.org/wp-content/uploads/ 2010/07/CAFF-Lessons-Local-Distribution102814.pdf

Alavanja, M. C., Hoppin, J. A., \& Kamel, F. (2004). Health effects of chronic pesticide exposure: Cancer and neurotoxicity. Annual Review of Public Health, 25, 155-197. http://dx.doi.org/10.1146/ annurev.publhealth.25.101802.123020

Bagdonis, J. M., Hinrichs, C. C., \& Schafft, K. A. (2009). The emergence and framing of farm-to-school initiatives: Civic engagement, health and local agriculture. Agriculture and Human V alues, 26(1-2), 107-119. http://dx.doi.org/10.1007/s10460-0089173-6

Barham, J., Tropp, D., Enterline, K., Farbman, J., Fisk, J., and Kiraly, S. (2009). Regional food bub resource guide. Washington, D.C.: U.S. Department of Agriculture, Agricultural Marketing Service. http://dx.doi.org/10.9752/MS046.04-2012

Bay Cities Produce. (n.d.). Local food purchasing. Retrieved June 6, 2013, from http://www.baycities produce.com/about-us/local-food-purchasing

Berkenkamp, J. (2006). Making the farm/ school connection: Opportunities and barriers to greater use of locally-grown produce in public schools. Department of Applied Economics, University of Minnesota. Retrieved from http://www.iatp.org/files/258 2 96621.pdf

Blatner, D. J. (2012). 20 things you didn't know about baby carrots [Web log post]. Retrieved from Huffington Post Healthy Living: http://www. huffingtonpost.com/dawn-jackson-blatner-rd-cssdldn/facts-baby-carrots b 2162178.html

Bloom, J. D., \& Hinrichs, C. C. (2011). Moving local food through conventional food system infrastructure: Value chain framework comparisons and insights. Renewable Agriculture and Food Systems, 26(1), 13-23. http://dx.doi.org/10.1017/S1742170510000384

California Department of Food and Agriculture. (n.d.). California agricultural production statistics.

Retrieved July 17, 2013, from http://www.cdfa.ca.gov/statistics/
Cohen, N., \& Derryck, D. (2011). Corbin Hill Road Farm Share: A hybrid food value chain in practice. Journal of Agriculture, Food Systems, and Community Development, 1(4), 85-100. http://dx.doi.org/10.5304/jafscd.2011.014.011

Conner, D. S., Nowak, A., Berkenkamp, J., Feenstra, G. W., Kim, J. V., Liquori, T., \& Hamm, M. W. (2011). Value chains for sustainable procurement in large school districts: Fostering partnerships. Journal of Agriculture, Food Systems, and Community Development, 1(4), 55-68. http://dx.doi.org/10.5304/jafscd.2011.014.005

Diamond, A., \& Barham, J. (2011). Money and mission: Moving food with value and values. Journal of Agriculture, Food Systems, and Community Development, 1(4), 101-117. http://dx.doi.org/10.5304/jafscd.2011.014.013

Feenstra, G., Allen, P., Hardesty, S., Ohmart, J., \& Perez, J. (2011). Using a supply chain analysis to assess the sustainability of farm-to-institution programs. Journal of Agriculture, Food Systems, and Community Development, 1(4), 69-84. http://dx.doi.org/10.5304/jafscd.2011.014.009

Gereffi, G., Lee, J., \& Christian, M. (2009). US-based food and agricultural value chains and their relevance to healthy diets. Journal of Hunger \& Environmental Nutrition, 4(3-4), 357-374. http://dx.doi.org/10.1080/19320240903321276

Greenwood, D. J., \& Levin, M. (2007). Introduction to action research: Social research for social change. Thousand Oaks, California: Sage Publications.

Guthman, J. (2004). Agrarian dreams: The paradox of organic farming in California. Berkeley, California: University of California Press.

Harvie, J. (2008). Menu of change: Healthy food in health care. Reston, Virginia: Health Care Without Harm. Retrieved from http://www.healthyfoodinhealthcare.org

Health Care Without Harm [HCWH]. (n.d.). Healthy food in health care: A pledge for fresh, local, sustainable food. Retrieved from https://noharmuscanada.org/sites/default/files/documentsfiles/637/Healthy Food in Health Care.pdf

HCWH. (2012, March 1). Bay Area hospitals aggregate demand to push the market for certified-humane, cage-free eggs [Press release]. Retrieved from https://noharm-uscanada.org/articles/pressrelease/us-canada/bay-area-hospitals-aggregatedemand-push-market-certified-humane 
HCWH. (2014, May 20). Farm Fresh Healthcare Project how-to guide details innovative model to increase local, organic produce in hospitals [Press release]. Retrieved from https://noharm-uscanada.org/ articles/press-release/us-canada/farm-freshhealthcare-project-how-guide-details-innovativemodel

Hinrichs, C. C. (2003). The practice and politics of food system localization. Journal of Rural Studies, 19(1), 33-45. http://dx.doi.org/10.1016/S07430167(02)00040-2

Hoppe, R., Perry, J., \& Banker, D. E. (2000). ERS farm typology for a diverse agricultural sector (Agriculture Information Bulletin No. AIB-759). Washington, D.C.: United States Department of Agriculture [USDA], Economic Research Service. Retrieved from http://www.ers.usda.gov/publications/aibagricultural-information-bulletin/aib759.aspx

Izumi, B. T. (2008). Farm to school programs in public K-12 schools in the United States: Perspectives of farmers, food service professionals, and food distributors [Doctoral dissertation, UMI No. 3331933]. Michigan State University, Ann Arbor, Michigan.

Izumi, B. T., Wright, D. W., \& Hamm, M. W. (2010). Farm to school programs: Exploring the role of regionally-based food distributors in alternative agrifood networks. Agriculture and Human Values, 27(3), 335-350. http://dx.doi.org/10.1007/s10460009-9221-x

Kaufman, P. R., Handy, C., McLaughlin, E. W., Park, K., \& Green, G. M. (2000). Understanding the dynamics of produce markets: Consumption and consolidation growth (Agriculture Information Bulletin No. AIB-758). Washington, D.C.: USDA Economic Research Service. Retrieved from http://www.ers.usda.gov/ publications/aib-agricultural-informationbulletin/aib758.aspx

King, R. P., Hand, M. S., DiGiacomo, G., Clancy, K., Gomez, M. I., Hardesty, S. D., . . McLaughlin, E. W. (2010). Comparing the structure, size, and performance of local and mainstream food supply chains (Economic Research Report No. ERR-99). Washington, D.C.: USDA Economic Research Service. Retrieved from http://www.ers.usda.gov/publications/erreconomic-research-report/err99.aspx

Kirschenmann, F., Stevenson, S., Buttel, F., Lyson, T. A., \& Duffy, M. (2008). Why worry about agricul- ture of the middle? In F. Kirschenmann, S. Stevenson, F. Buttel, T. A. Lyson, \& M. Duffy (Eds.), Food and the mid-level arm: Renewing an agriculture of the middle (pp. 3-22). Cambridge, Massachusetts: MIT Press. http://dx.doi.org/ $10.7551 /$ mitpress / 9780262122993.003 .0001

Klein, K. (2012, October 12). A new prescription for the local food movement. The Nation. http://www.thenation.com/article/170526/newprescription-local-food-movement

Klein, K. (2014a). The Farm Fresh Healthcare Project: A how-to guide. San Francisco, California: San Francisco Bay Area Physicians for Social Responsibility, Health Care Without Harm, and Community Alliance with Family Farmers. Retrieved from https://noharm-uscanada.org/documents/farmfresh-healthcare-project-how-guide

Klein, K. (2014b, October 22). From farm to patient tray: Retrofitting the supply chain to meet hospitals' demand for local food [Online article]. Retrieved from https://goodfoodweb.com/articles/fromfarm-to-patient-tray-retrofitting-the-supply-chainto-meet-hospital

Lerman, T., Feenstra, G., \& Visher, D. (2012). A practitioner's guide to resources and publications on food hubs and values-based supply chains. Davis, California: University of California [UC] Sustainable Agriculture Research and Education Program. Retrieved from http://russellranch.ucdavis.edu/resources/ publications $/ \mathrm{KYF} \% 20$ grey $\% 20$ literature $\% 20$ review $\% 20 \mathrm{GF} \% 204-15 \% 20 \mathrm{FINAL}$ wcover.pdf

Lerman, T. (2012). A review of scholarly literature on valuesbased supply chains. Agricultural Sustainability Institute, Davis, California: UC Sustainable Agriculture Research and Education Program. Retrieved from http://www.sarep.ucdavis.edu/sfs/VBSCLiterature Review.Lerman.5.31.12 compressed.pdf

Local Orbit. (n.d.). Local Orbit [Home page]. Retrieved from http://localorbit.com/

Lyson, T. A. (2004). Civic agriculture: Reconnecting farm, food, and community. Lebanon, New Hampshire: Tufts University Press.

Lyson, T. A., Stevenson, G. W., \& Welsh, R. (2008). Food and the mid-level farm: Renewing an agriculture of the middle. Cambridge, Massachusetts: MIT Press. http://dx.doi.org/10.7551/mitpress/97802621229 $\underline{93.001 .0001}$ 
Martinez, S. (2007). The U.S. food marketing system: Recent developments, 1997-2006. Washington, D.C.: USDA Economic Research Service.

Minkler, M., \& Wallerstein, N. (2008). Part one: Introduction to CBPR: New issues and emphases. In M. Minkler \& N. Wallerstein (Eds.), Communitybased participatory research for health: From process to outcomes (2nd Ed., pp. 3-23). San Francisco, California: Jossey-Bass.

Perrett, A. (2007). The infrastructure of food procurement and distribution: Implications for farmers in western North Carolina. Asheville, North Carolina: Appalachian Sustainable Agriculture Project. Retrieved from http://asapconnections.org/downloads/growinglocal-expanding-the-western-north-carolina-foodand-farm-economy-full-report

Sachs, E., \& Feenstra, G. (2008). Emerging local food purchasing initiatives in northern California hospitals.

Davis, California: UC Sustainable Agriculture Research and Education Program. Retrieved from http://www.sarep.ucdavis.edu/sfs/files/Farm To Hospital_WebFinal.pdf

Sage, C. (2003). Social embeddedness and relations of regard: Alternative 'good food' networks in southwest Ireland. Journal of Rural Studies, 19(1), 47-60. http://dx.doi.org/10.1016/S0743-0167(02)00044$\underline{\mathrm{X}}$

Selfa, T., \& Qazi, J. (2005). Place, taste, or face-to-face? Understanding producer-consumer networks in "local" food systems in Washington State. Agriculture and Human Values, 22(4), 451-464. http://dx.doi.org/10.1007/s10460-005-3401-0

Sirois, E., Pryor, K., Klein, K., \& Thottathil, S. (2013). Menu of change: Healthy food in health care (A 2013 Program Report with Highlights, Awards and Survey Results). Reston, Virginia: Health Care Without Harm. Retrieved from http://noharm-uscanada. org/sites/default/files/documents-files/883/ Menu $\% 2520$ Of $\% 2520$ Change $\% 2520$ Report $\% 2520$ 2013 R3.pdf

Stevenson, G. W., \& Pirog, R. (2008). Values-based supply chains: Strategies for agrifood enterprises of the middle. In A. Author \& B. Author (Eds.), Food and the mid-level farm: renewing an agriculture of the middle (pp. 119-146). Cambridge, Massachusetts: MIT Press

Sutton, P., Wallinga, D., Perron, J., Gottlieb, M., Sayre, L., \& Woodruff, T. (2011). Reproductive health and the industrialized food system: A point of intervention for health policy. Health Affairs, 30(5), 888-897. http://dx.doi.org/10.1377/hlthaff.2010.1255

Vogt, R. A., \& Kaiser, L. L. (2008). Still a time to act: A review of institutional marketing of regionallygrown food. Agriculture and Human V alues, 25(2), 241-255. http://dx.doi.org/10.1007/s10460-0079106-9

Walker, R. A. (2004). The conquest of bread: 150 years of agribusiness in California. New York: The New Press. 